\title{
Evaluation of The Ethmoid Bone Using by Cone Beam Computed Tomography In Turkish Subpopulation
}

\author{
Ceren Aktuna Belgin ${ }^{1}$, Seval Bayrak ${ }^{2}$, Kaan Orhan $^{3}{ }^{\circledR}$ \\ ${ }^{1}$ Department of Dentomaxillofacial Radiology, Faculty of Dentistry, Hatay Mustafa Kemal University, Hatay, Turkey. \\ ${ }^{2}$ Department of Dentomaxillofacial Radiology, Faculty of Dentistry, Bolu Abant Izzet Baysal University, Bolu, Turkey. \\ ${ }^{3}$ Dentomaxillofacial Radiology Department, Faculty of Dentistry, Ankara University, Ankara, Turkey.
}

Correspondence Author: Ceren Aktuna Belgin

E-mail: dtcaktuna@gmail.com

Received: $05.05 .2020 \quad$ Accepted: 25.09 .2021

\begin{abstract}
Objective: The objective of this retrospective study was to evaluated anatomical structures of ethmoid bone on cone beam computed tomography (CBCT) images in a Turkish subpopulation.

Methods: The CBCT images of 200 patients (116 female and 84 male), between the age of 18 and 50 years, who met the study criteria were selected randomly. The medial ethmoid roof height (MERH), cribriform plate height (CP), the height of the lateral lamella of the cribriform plate (LLCP) were measured. All the data were grouped by age, side, and gender.

Results: For MERH; the mean heights for the left and the right side were $25.55 \pm 3.00 \mathrm{~mm}$ and $25.24 \pm 3.01 \mathrm{~mm}$, respectively. There was no significant difference between right MERH and genders ( $p>0.05$ ). The mean LLCP heights on the right and left sides were $4.98 \pm 2.12 \mathrm{~mm}$ and $4.49 \pm 1.64 \mathrm{~mm}$, respectively. It was found that LLCP height did not have a statistically significant correlation with gender ( $p>0.05)$. The average of right and left CPH were calculated $20.55 \pm 2.61 \mathrm{~mm}$ and $20.82 \pm 2.75 \mathrm{~mm}$, respectively. Both the right and left CPH were significantly higher in males $(p<0.05)$. Also, there was no correlation between the height of the anatomical structures of the evaluated ethmoid bone and the increase or decrease in age $(p>0.05)$.

Conclusion: Morphological differences in the anatomy of ethmoid bone were shown in this study. The anatomical structures showing changes due to factors such as side, age, gender, and race should be examined in three dimensions before the operation.

Keywords: Anatomy, cone beam computed tomography, cribriform plate, ethmoid roof
\end{abstract}

\section{INTRODUCTION}

The anatomical form of the paranasal sinuses should be carefully examined to prevent complications before "Functional Endoscopic Sinus Surgery" (FESS), which is used in the treatment of sinonasal pathologies (1). In surgical interventions, a fracture of the cribriform lamina may result in cerebrospinal fluid (CSF) flow, meningitis, and dura mater, and bone defects that may lead to intracranial hypotension. These risks increase in the presence of length increase or deviation in cribriform lamella $(2,3)$. The ethmoid bone roof is composed of the ethmoidal fovea and the lateral lamella of the cribriform plate (LLCP) medially. The LLCP is the thinnest and most indefensible landmark of the skull, so it is the most generally injured part of the skull base during FESS or paranasal sinuses surgery procedures. Therefore, the penetration risk of the anterior cranial fossa in surgical interventions also increases, and complications such as cerebral destruction, hemorrhage, and CSF discharge may develop $(4,5)$.

Cone beam computed tomography (CBCT) is often preferred in all areas of dentistry, as the three-dimensional image can be obtained with a low radiation dose. CBCT, which can be used in many areas such as diagnosis and treatment planning in complicated cases requiring multidisciplinary study, an examination of paranasal sinuses, imaging of osteomeatal structures, has eliminated some disadvantages of conventional two-dimensional radiographs. The complex anatomical form of the maxillofacial region can be evaluated without the superposition of other anatomical structures with high-resolution CBCTs. The advantages of CBCTs are the three-dimensional examination of structures in axial, sagittal, coronal, and cross-sectional planes (6). 
This study, it was aimed to evaluate morphometrically the anatomical structures of the ethmoid bone on CBCT images in a Turkish subpopulation.

\section{METHODS}

This retrospective study was approved by the Local Ethics Committee of Bolu Abant İzzet Baysal University, (decision date: 20.01.2020, decision number: 34) and the study protocol was conducted following the principles of the Declaration of Helsinki. This study involved the evaluation of CBCTs (images) that were taken previously for various reasons in the dentomaxillofacial radiology clinic. Patients were selected who were over 18 years, had no sinonasal pathology (tumor or cyst, serious rhinosinusitis), no history of trauma and surgical operation that will disrupt the integrity of the paranasal region. Also, inadequate quality $\mathrm{CBCT}$ images that could not be diagnosed were excluded from the study.

The CBCT images of 200 patients (116 female and 84 male), between the ages of 18 and 50 years old (mean age 21.57士 4,793 years) who met the study criteria were selected randomly from the digital database of Bolu Abant İzzet Baysal University Faculty of Dentistry.

\subsection{CBCT Imaging}

$\mathrm{CBCT}$ images were obtained with an I-CAT device (Imaging Sciences International, Hatfield, PA) with $16 \times 9,16 \times 10,16$ $\times 11,16 \times 12$, or $16 \times 13 \mathrm{~cm}$ image area, $120 \mathrm{kVp}, 5 \mathrm{~mA}, 8.9-\mathrm{s}$ acquisition time irradiation parameters. All measurements were calculated in $0.3 \mathrm{~mm}$ slice thickness in coronal sections via I-CAT Vision software (Imaging Science International) by a single observer.

The following measurements were assessed $(7,8)$ :

1. The medial ethmoid roof height (MERH); measured vertical line drawn from the medial ethmoid roof to the horizontal plane in left and right side (The horizontal plane was represents the horizontal line passing through the infraorbital nerves). (Figure 1A).

2. Cribriform plate height (CPH); a measured vertical line drawn from the cribriform plate to the horizontal plane on the left and right side (Figure 1B).

3. The LLCP height; subtracted the $\mathrm{CPH}$ from the $\mathrm{MERH}$.
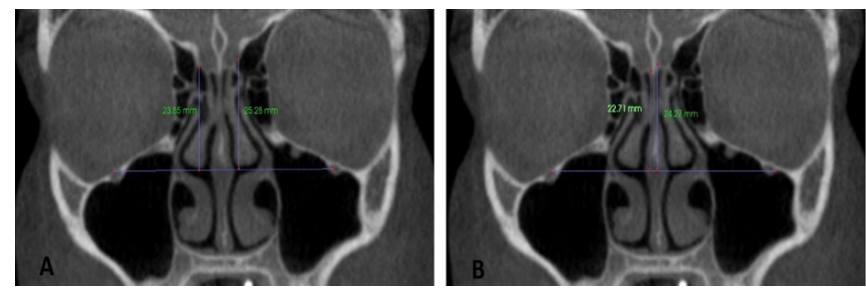

Figure 1. The measurement of left and right medial ethmoid roof height (A) and left and right cribriform plate height (B) on coronal section. The horizontal line in both images was represents the line passing through the infraorbital nerves.
All measurements were performed twice by the same observer and recorded in millimeters using a preadsheet (Microsoft Office Excel, Redmond, WA) and made on the same laptop computer (Dell Inc., Round Rock, TX, USA). To test intra-observer agreement, $20 \%$ of all measurements were repeated after two weeks. All the data were grouped and compared by age, gender and side.

\subsection{Statistical Analysis}

SPSS 23.0 software (SPSS Inc., Chicago, IL, USA) was used for statistical analyses, and data are given as mean \pm standard deviation. The compatibility of the parameters to normal distribution was calculated by the Kolmogorov-Smirnov test. Wilcoxon sign rank test was used to compare right-left measurements in paranormally distributed data. Differences between genders were evaluated by the Mann-Whitney $U$ test and the correlations between measurements were calculated with the Spearman rank test. The significance level was considered at $p<0.05$.

\section{RESULTS}

The intraobserver intraclass correlation (ICC) value was 0.904 (95\% Cl: 0.743-0.942). Of the 200 CBCT analyzed, 116 (58\%) were female and 84 (42\%) were male. The average LLCP heights on the right and left sides were $4.98 \pm 2.12 \mathrm{~mm}$ and $4.49 \pm 1.64 \mathrm{~mm}$, respectively. The mean right LLCP height was found to be statistically significantly higher than the left side $(p=0.001)$. In the female, the mean of right and left LLCP height were $5.07 \pm 2.07 \mathrm{~mm}$ and $4.48 \pm 1.63 \mathrm{~mm}$, respectively. In the male, the mean of right and left LLCP height were $4.83 \pm 2.21$ and $4.50 \pm 1.66 \mathrm{~mm}$, respectively. It was found that LLCP height did not have a statistically significant correlation with gender $(p>0.05)$ (Table 1$)$. There was a statistically significant positive correlation among LLCP height sides $(p<0.05)$. There was a statistically significant negative correlation between LLCP and CPH $(p<0.05)$. No association was calculated between LLCP and other parameters ( $p>0.05)$ (Table 2).

The average of right and left MERH were calculated $25.55 \pm 3.00$ $\mathrm{mm}$ and $25.24 \pm 3.01 \mathrm{~mm}$, respectively. Also, there was no significant difference between left and right MERH ( $p>0.05)$. There was no significant difference between right MERH and genders ( $p>0.05$ ) although the left MERH was higher in males $(p<0.05)$ (Table 1). A statistically significant relationship was found between LLCP and MERH $(p<0.05)$. There was a positive relationship between $\mathrm{CPH}$ and MERH $(p<0.05)$. No relation was detected between other parameters and MERH ( $p>0.05$ ) (Table 2).

The average of right and left $\mathrm{CPH}$ were calculated $20.55 \pm 2.61$ $\mathrm{mm}$ and $20.82 \pm 2.75 \mathrm{~mm}$, respectively. There was a statistically significant positive relationship between right and left $\mathrm{CPH}(p=0.001)$. Both the right and left $\mathrm{CPH}$ were significantly higher in males $(p<0.05)$ (Table 1$)$. There was no statistically significant difference between any parameters and $\mathrm{CPH}(\mathrm{p}>0.05)$ (Table 2). Also, there was no correlation 
between the height of the anatomical structures of the evaluated ethmoid bone and the increase or decrease in age ( $p>0.05$ ) (Table 2).

Table 1. Comparison of anatomical structures with gender

\begin{tabular}{|c|c|c|c|c|}
\hline & & $\begin{array}{l}\text { Male } \\
(\mathrm{N}: 84)\end{array}$ & $\begin{array}{l}\text { Female } \\
\text { (N:116) }\end{array}$ & $p$ \\
\hline \multirow[t]{4}{*}{ Right MERH (mm) } & Mean & 25.7646 & 25.4255 & \multirow[t]{4}{*}{0.514} \\
\hline & SD & 2.95527 & 3.03387 & \\
\hline & Minimum & 19.61 & 19.22 & \\
\hline & Maximum & 37.77 & 37.77 & \\
\hline \multirow[t]{4}{*}{ Left MERH (mm) } & Mean & 25.8270 & 24.8952 & \multirow[t]{4}{*}{$0.017^{*}$} \\
\hline & SD & 2.46627 & 3.25191 & \\
\hline & Minimum & 18.05 & 5.66 & \\
\hline & Maximum & 31.92 & 31.92 & \\
\hline \multirow[t]{4}{*}{ Right CPH (mm) } & Mean & 20.9329 & 20.3362 & \multirow[t]{4}{*}{$0.049 *$} \\
\hline & SD & 2.60014 & 2.60806 & \\
\hline & Minimum & 14.03 & 14.03 & \\
\hline & Maximum & 26.73 & 28.15 & \\
\hline \multirow[t]{4}{*}{ Left CPH (mm) } & Mean & 21.3239 & 20.6110 & \multirow[t]{4}{*}{$0.029 *$} \\
\hline & SD & 2.63431 & 2.79379 & \\
\hline & Minimum & 13.25 & 13.25 & \\
\hline & Maximum & 26.73 & 28.28 & \\
\hline \multirow[t]{4}{*}{ Right LLCP (mm) } & Mean & 4.8318 & 5.0779 & \multirow[t]{4}{*}{0.218} \\
\hline & SD & 2.21481 & 2.07025 & \\
\hline & Minimum & 1.58 & 0.65 & \\
\hline & Maximum & 15.83 & 15.83 & \\
\hline \multirow[t]{4}{*}{ Left LLCP (mm) } & Mean & 4.5031 & 4.4875 & \multirow[t]{4}{*}{0.749} \\
\hline & SD & 1.66830 & 1.63370 & \\
\hline & Minimum & 0.29 & 1.29 & \\
\hline & Maximum & 8.30 & 14.33 & \\
\hline
\end{tabular}

* Significant differences $(p<0.05)$ are indicated in bold. SD: Standart deviation. N: patient. MERH: Medial Etmoit Roof Height. CPH: Cribroform Plate Height. LLCP: Lateral Lamella of Cribroform Plate. mm: millimeter.

Table 2. Comparison of anatomical structures with each other

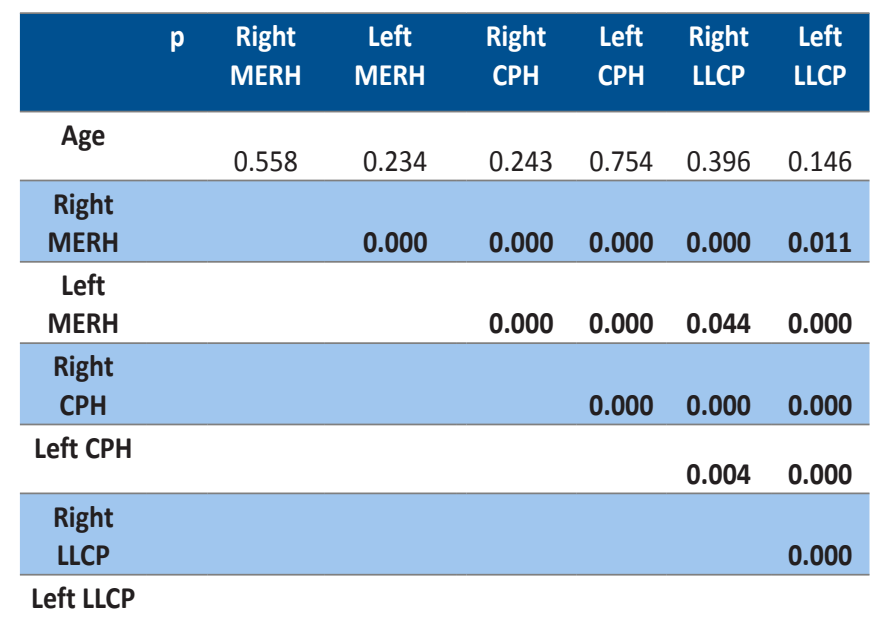

* Significant differences $(p<0.05)$ are indicated in bold. MERH: Medial Etmoit Roof Height. CPH: Cribroform Plate Height. LLCP: Lateral Lamella of Cribroform Plate.

\section{DISCUSSION}

To prevent possible complications such as penetration of the anterior cranial fossa during operation and the occurring cerebral damage, cerebral hemorrhage, and cerebrospinal fluid fistula, the anatomy of the anterior skull base and ethmoid bone should be carefully examined and the lengths of the anatomical structures should be measured. The lateral lamella, which is a thin bone part of $\mathrm{CPH}$, both parts the medial wall of the ethmoid roof and constitutes the upper border of the operative region in FESS operations. This structure is important for the risk of damage in being easily damaged in the operations in the posterior medial concha or posterior ethmoid bone region. (9). In our study, it was proposed to use CBCT images in accordance with the literature due to the complex anatomic of the ethmoid bone we examined and measured. As the depth of the $\mathrm{CPH}$ increases, the lateral lamella length increases. This also increases the risk of developing complications during surgery. $(6,10-12)$. In this study, to provide the best $\mathrm{CPH}$ measurement, the coronal section that shows this region most clearly is preferred. Using radiological means to determine the ethmoid roof is critical for designing the superior limit of the dissection $(13,14)$.

In the literature, measurements of ethmoid bone components were made in different races. Munoz-Lejia et al. (15) stated that in Mexican, the mean right $\mathrm{CPH}$ was $8.94 \mathrm{~mm}$ and 10.21 $\mathrm{mm}$ in men and women, respectively also the mean left $\mathrm{CPH}$ was $8.99 \mathrm{~mm}$ and $10.20 \mathrm{~mm}$ for men and women, respectively. They found statistical differences between the right and left sides in both genders. Meloni et al. (16) calculated the mean $\mathrm{CPH}$ was $5.9 \mathrm{~mm}$ (range 1.3-17 mm) in Italians. Similarly, Gera et al. (17) showed that the mean $\mathrm{CPH}$ was $5.4 \pm 1.7 \mathrm{~mm}$ (range, 2.4-10.3 mm). The mean $\mathrm{CPH}$ in males was $5.6 \pm 1.7$ $\mathrm{mm}$ (range, $2.4-10.1 \mathrm{~mm}$ ) while in females it was $5.2 \pm 1.7$ $\mathrm{mm}$ (range, 2.9-10.3 $\mathrm{mm}$ ). They stated that these differences were found not significant. Erdogan et al. (18) found the right $\mathrm{CPH}$ was $25.01 \mathrm{~mm}$ (range, 18-32.1 mm), and the left $\mathrm{CPH}$ was $25.38 \mathrm{~mm}$ (range, 18.5-36.1 mm). When we compare present study with the literature, it is seen that the $\mathrm{CPH}$ is higher than the average. The reason for this is thought to be the differences in measurement points. In our study, the measurement of $\mathrm{CPH}$ was based on the distance of the cribriform plate to the horizontal line. The reason why take this distance as a basis is to determine the risk of skull base injury during the operation according to the change in this distance in the TMS classification (19). On the other hand, the findings of our study were similar to the study of Erdogan et al. (18) in the Turkish population. This can be interpreted as the fact that the race factor is effective in the morphometric measurements of anatomical structures. This could be the basis for future work. Paber et al. (20) reported that in their study, the mean LLCP height among Filipinos was $2.21 \mathrm{~mm}$. They found were no significant difference in the LLCP height among age groups and sides but a significant difference between genders. Similarly, Alazzawi et al. (21) showed that in the Malaysian population, the mean LLCP height was $2.64 \mathrm{~mm}$ and the left LLCP height was higher from the right side. Bista et al. (22) found that in their study the mean height of LLCP was $2.8 \mathrm{~mm}$ in African. 
The LLCP height was calculated greater on the right side in $56 \%$ of patients and was greater on the left side in $38 \%$ of patients. Abdullah et al. (23) stated that the mean LLCP height was 7.44 $\pm 1.32 \mathrm{~mm}$ in the Asian population (Malays, Chinese, Indian). Erdogan et al. (18) calculated the right LLCP height was 5.78 $\mathrm{mm}$ (range 2.1-10.3 mm), and the left LLCP height was 5.98 $\mathrm{mm}$ (range, 1-10.9 $\mathrm{mm}$ ). In present study, we found the mean of right and left LLCP height were $4.98 \pm 2.12 \mathrm{~mm}$ and 4.49 $\pm 1.64 \mathrm{~mm}$, respectively in the Turkish subpopulation. When we compared the results, it was seen that the LLCP height in the Turkish population was higher than Africans and Filipinos, similarly Turkish population and lower than Asian populations.

\section{CONCLUSION}

In our study, the relationships between morphometric measurements of ethmoid bone components and, height, age, and gender were shown in the Turkish subpopulation. It was seen that the age factor did not affect the length of these anatomical structures, but race, gender, and the measuring side affected these measurements. It should not be ignored that there may be differences in the operations related to the ethmoid bone in terms of gender and sides. Therefore evaluation of the anatomical structure of ethmoid bone by three-dimensional imaging is recommended to prevent complications that may occur in sinus surgeries.

\section{REFERENCES}

[1] Wigand ME, Hosemann WG. Results of endoscopic surgery of the paranasal sinuses and anterior skull base. J Otolaryngol 1991;20:385-390.

[2] Hoang JK, Eastwood JD, Tebbit CL, Glastonbury CM. Multiplanar sinus CT: a systematic approach to imaging before functional endoscopic sinus surgery. AJR Am J Roentgenol 2010;194:527536.

[3] Erdem G, Erdem T, Miman MC, Ozturan O. A radiological anatomic study of the cribriform plate compared with constant structures. Rhinology 2004;42:225-229.

[4] Gumus C, Yildirim A. Radiological correlation between pneumatization of frontal sinus and height of fovea ethmoidalis. Am J Rhinol 2007;21:626-628.

[5] Kayabasi S, Hizli O, Ozkan D. Does paranasal sinus development affect olfactory fossa depth and lateral lamella length?. Laryngoscope 2019;129(11):2458-2463

[6] Orhan K. Diş hekimliğinde konik ışınlı komputerize tomografinin (KIKT) yeri ve önemi. Yeditepe J Dent 2012;3:6-17 (Turkish).

[7] Skorek A, Tretiakow D, Szmuda T, Przewozny T. Is the Keros classification alone enough to identify patients with the 'dangerous ethmoid'? An anatomical study. Acta Otolaryngol 2017;137:196-201.

[8] Adeel M, Ikram M, Rajput MS, Arain A, Khattak YJ. Asymmetry of lateral lamella of the cribriform plate: a software-based analysis of coronal computed tomography and its clinical relevance in endoscopic sinus surgery. Surg Radiol Anat 2013;35:843-847.

[9] Jang YJ, Park HM, Kim HG. The radiographic incidence of bony defects in the lateral lamella of the cribriform plate. Clin Otolaryngol Allied Sci 1999;24:440-442.

[10] Savvateeva DM, Güldner C, Murthum T, Bien S, Teymoortash A, Werner JA, Bremke M. Digital volume tomography (DVT) measurements of the olfactory cleft and olfactory fossa. Acta Otolaryngol 2010;130:398-404.

[11] Güldner C, Diogo I, Windfuhr J, Bien S, Teymoortash A, Werner JA, Bremke M. Analysis of the fossa olfactoria using cone beam tomography (CBT). Acta Otolaryngol 2011;131:72-78.

[12] Bremke M, Sesterhenn AM, Murthum T, Al Hail A, Bien S, Werner JA. Digital volume tomography (DVT) as a diagnostic modality of the anterior skull base. Acta Otolaryngol 2009;129:1106-1114.

[13] McMains KC. Safety in endoscopic sinus surgery. Curr Opin Otolaryngol Head Neck Surg 2008;16:247-251.

[14] Ulualp SO. Complications of endoscopic sinus surgery: appropriate management of complications. Curr Opin Otolaryngol Head Neck Surg 2008;16:252-259.

[15] Muñoz-Leija MA, Yamamoto-Ramos M, Barrera-Flores FJ, Treviño-González JL, Quiroga-Garza A, Méndez-Sáenz MA, et al. Anatomical variations of the ethmoidal roof: differences between men and women. Eur Arch Otorhinolaryngol 2018;275:1831-1836

[16] Meloni F, Mini R, Rovasio S, Stomeo F, Teatini GP. Anatomic variations of surgical importance in ethmoid labyrinth and sphenoid sinus. A study of radiology anatomy. Surg Radiol Anat 1992;14:65-70.

[17] Gera R, Mozzanica F, Karligkiotis A, Preti A, Bandi F, et al. Lateral lamella of the cribriform plate, a keystone landmark: proposal for a novel classification system. Rhinology 2018;56:65-72.

[18] Erdogan S, Keskin IG, Topdag M, Ozturk M, Sari F, Mutlu F. Ethmoid roof radiology; analysis of lateral lamella of cribriform plate. Otolaryngol Pol 2015;69:53-57.

[19] Abdullah B, Chew SC, Aziz ME, Shukri MN, Husain S, Joshua SW, Wang DY, Snidvongs K. A new radiological classification for the risk assessment of anterior skull base injury in endoscopic sinus surgery. Sci Rep 2020:10;4600.

[20] Paber JE, Salvador M, Villarta R. Radiographic analysis of the ethmoid roof based on Keros classification among Filipinos. Philipp J Otolaryngol Head Neck Surg 2008;23:15-19.

[21] Alazzawi S, Omar R, Rahmat K, Alli K. Radiological analysis of the ethmoid roof in the Malaysian population. Auris Nasus Larynx 2012;39:393-396.

[22] Bista M, Maharjan M, Kafle P, Shrestha S, KC T. Computed tomographic assessment of lateral lamella of cribriform plate and comparison of depth of olfactory fossa. JNMA J Nepal Med Assoc 2010;49:92-95.

[23] Abdullah B, Lim EH, Mohamad H, Husain S, Aziz ME, Snidvongs $\mathrm{K}$, Wang Y, Musa KI. Anatomical variations of anterior ethmoidal artery at the ethmoidal roof and anterior skull base in Asians. Surg Radiol Anat 2019;41:543-550. 